\title{
Hepatitis B infection and risk factors among children living with HIV in Yaounde, Cameroon: an integrated management
}

Fokam Joseph ${ }^{1,2,3}$, Kamga Wouambo Rodrigue ${ }^{4,5^{*}}$, Tchatchouang Serges ${ }^{6}$, Nguwoh Philippe Salomon ${ }^{5,7}$, Taheu Ngounouh Christian ${ }^{8}$, Tommo Tchouaket Michel Carlos ${ }^{1}$, Fosso Samuel ${ }^{9}$, Njom-Nlend Anne-Esther ${ }^{10}$, Vittorio Colizzi ${ }^{11,12}$ and Nkenfou Nguefeu Celine ${ }^{1,13}$

\begin{abstract}
Background: The endemicity of hepatitis B virus (HBV) prompted the systematic immunization of newborns in Cameroon since 2005. In the frame of a considerable burden of HIV/HBV co-infection (17.5\%), monitoring HBV among children living with HIV (CLHIV) would guide toward HIV/HBV integrated paediatric care. We sought to ascertain the prevalence and determinants of HBV infection in the population of CLHIV and performance of commonly used rapid diagnosis tests (RDTs).
\end{abstract}

Methods: Cross-sectional study conducted from February through June 2017 in a subset of CLHIV $\leq 15$ years old at the Essos Hospital Centre, Yaounde, Cameroon. HBV was tested by HBsAg ELISA sandwich in duplicates for each sample, and the mean optical density was calculated. The Determinants of HBV-prevalencewere evaluated, and $p<0.05$ was the significance threshold. The performance of two HBV RDTs (Diaspot vs. HBV-5) was evaluated in comparison to ELISA (used as gold standard).

Results: Of the 83 CLHIV enrolled (54.2\% female, mean age 8.7 [ \pm 3.8 ] years, 60\% vaccinated against HBV, all breastfed), HBV-prevalence was $2.41 \%$ (2/83). HBV-positivity was significantly associated with unknown maternal HBV status (2.9\% [2/69] vs. $0.0 \%[0 / 14], p=0.0097)$ and vaginal delivery (2.4\% [2/82] vs. 0.0\% [0/1], $p=0.0018)$. Moreover, the most likely to be positive were aged 11 and 15 years, and had experienced neither anti-HBV vaccination nor anti-HBV serum administration, and both had not been treated with any antiseptic solution at birth. Regarding the performance of Diaspot vs. HBV-5 respectively, sensitivity was 100\% (2/2) vs. $50 \%(1 / 2)$, while specificity was $100 \%(45 / 45)$ vs. $97.8 \%$ (44/45); positive and negative predictive values of Diaspot versus HBV-5 were respectively 100\% (2/2) and 100\% (45/45) versus 50\% (1/2) and 97.8\% (44/45).

Conclusion: HBV-infection in the population of CLHIV appears at a moderate prevalence, suggesting a decreased burden likely due to preventive measures including the wide vaccine coverage. Focusing on mothers with unknown HBV status and promoting safer delivery mode (caesarean section) for HBV-positive motherswould contribute toward pediatric HBV elimination. In context of limited resources, Diaspot test appears more reliable to rollout HBV-infection in the population of CLHIV. As findings are limited to a small sample size, studies on a wider population would be relevant.

Keywords: HBV infection, Risk factors, Children living with HIV/AIDS

\footnotetext{
* Correspondence: rodriguekamga89@yahoo.fr

${ }^{4}$ Faculty of Science, Department of Microbiology and Parasitology, University of Buea, Buea, Cameroon

${ }^{5}$ Department of Health Sciences, Estuary Academy and Strategic Institute (IUES/INSAM/ISSAS), Higher Institute of Health Applied Sciences, University of Buea, Buea, Cameroon

Full list of author information is available at the end of the article
}

(c) The Author(s). 2019 Open Access This article is distributed under the terms of the Creative Commons Attribution 4.0 International License (http://creativecommons.org/licenses/by/4.0/), which permits unrestricted use, distribution, and reproduction in any medium, provided you give appropriate credit to the original author(s) and the source, provide a link to the Creative Commons license, and indicate if changes were made. The Creative Commons Public Domain Dedication waiver (http://creativecommons.org/publicdomain/zero/1.0/) applies to the data made available in this article, unless otherwise stated. 


\section{Introduction}

HIV and hepatitis B virus (HBV) remain major public health concerns worldwide, with about 36.9 and 350 million people living respectively with HIV and chronic $\mathrm{HBV}$ (CHB) infections worldwide $[1,2]$. While $70 \%$ of the global HIV burden is found in sub-Saharan Africa (SSA), HBV is ubiquitous within the Asian (15\%) and African populations (8-40\%) [2], thus indicating a high risk of HIV/HBV copresence within the African populations. Of note, HIV/ HBV co-infection is characterized by a synergistic interaction between both viruses leading on one hand, to a rapid progression to AIDS defining event(s), and on the other hand, to an earlier development of hepatocellular carcinoma as compared to HBV mono-infected individuals [3]. Also, the probability of acquiring $\mathrm{CHB}$ is significantly higher in the frame of HIV infection, and this event becomes more worrisome for children at early age (80-90\% of infants aged below 1 year and $30-50 \%$ of children aged 1-4 years) infected with $\mathrm{HBV}$ end-up developing $\mathrm{CHB}$ infection $[4,5]$. Thus, in order to support the global effort of eliminating viral hepatitis, strategies toward integrated prevention and care for HIV/HBV would be essential, especially for paediatric populations for whom the risk of $\mathrm{CHB}$ is the highest $[2,3]$.

The common routes of HBV transmission among children are perinatal and horizontal during early childhood $[6,7]$. Of note, perinatal transmission was more frequent in Asia (from mother-to-child) while the horizontal was more in SSA (horizontally from infected household members or unsafe materials during early age) in year 1990 [8, 9]. Of relevance, "children detected positive for hepatitis B surface antigen ( $\mathrm{HBsAg}$ ) and envelope antigen (HBeAg) are highly contagious; over $85-90 \%$ of them are potential $\mathrm{CHB}$ carriers and liver cancer patients at adulthood, a condition that would be worsening in the context of co-infection with HIV [10-12]. In this context, ensuring an effective implementation of a preventive package would be helpful, starting from universal screening of $\mathrm{HBV}$ among pregnant women attending their first antenatal care (ANC), a systematic vaccination against $\mathrm{HBV}$ all pregnant women having a negative HBsAg result, providing HBV antibodies at birth to all vertically-exposed babies, and a universal vaccination of new-borns [13]. However, response to anti-HBV vaccine might vary according to age and HIV status, thereby indicating high vulnerability to HBV among children living with HIV (CLHIV) as we previously reported within a similar target population in Cameroon [13]. Thus, assessing the burden of HBV in CLHIV in Cameroon would help in understanding the current epidemiologic context and in designing interventions for greater protectiveness at country-level.

Even though Cameroon is experiencing declining trends of both HIV among adults and adolescents aged
15-49 years (from 4.3 to $3.4 \%$ ) and HBV (12.2 to $8.1 \%$ ), the country is still experiencing a generalized epidemic of both infections, suggesting consistent risks of paediatric infections and the need for evidence-based strategic interventions to support an integrated care $[14,15]$. Though data on HBV/HIV coinfection in children remain largely uncovered in several SSA countries, our previous findings from Cameroon indicate a poor immunological response to HBV-vaccine in the population of CLHIV, hence suggesting risks of HBV-infection in spite of vaccination [13]. Additionally, HBV/HIV prevalence remains high in several African countries (5-40\%), with $17.5 \%$ coinfection among pregnant women in Cameroon [7, 16-18] where the screening of HBV in new born babies is not yet systematically done. Furthermore, antiretroviral therapy (ART), for both children and adults living in SSA, usually entails molecules with anti-HBV activities (lamivudine [3TC], emtricitabine [FTC], tenofovir [TDF]), with limited evidence on its effects on HBV pathogenesis in the frame of co-infection with HIV in children $[16,17]$. Thus, understanding factors sustaining risks of HBV transmission to CLHIV is crucial for designing integrated but impactful strategies against HBV for CLHIV in SSA $[16,17]$.

Integrating $\mathrm{HBV}$ service delivery with HIV care requires the use of simple, affordable and rapid diagnostic tests (RDTs) for HBV screening in SSA settings [7, 13]. Of note, in spite of their high sensitivity and specificity, reference diagnostic assays remain costly, require sophisticated platforms and are time consuming [13]. In this frame, RDTs are highly encouraged and are widely used for HBV screening, but without a prior assessment of the diagnostic accuracy for ensuring clinical validation of result delivered locally [13]. Thus, assessing the performance of commonly used HBV RDTs in routine practice would prompt the rollout of HBV/HIV service integration and support the global effort toward elimination, especially in children known to have a higher risk of vulnerability to infection and rapid disease progression if co-infected.

The objectives of our study were to evaluate the prevalence of $\mathrm{HBV}$ in the population of CLHIV, determine factors associated with $\mathrm{HBV}$-infection in these children, and assess the diagnostic performance of two RDTs routinely used for HBV detection.

\section{Materials and methods}

Study design and settings

A hospital-based study targeting CLHIV visiting the HIV Care and Treatment Centre of the Essos Hospital Center (EHC) in Yaounde-Cameroon was conducted from February 3rd to June 30th, 2017. EHC was selected as the study sentinel site based on the availability of a paediatric care service, the availability of standard registers for monitoring individuals diagnosed HIV-positive, the 
management of ART following the national guidelines, and a cohort of CLHIV receiving ART on site. In fact, HIV testing is systematically performed across the country on each pregnant woman and each child vertically exposed to HIV unlike HBV testing, not yet widespread and consequently just done at times on pregnant women, children exposed infected or non-infected.

\section{Sample size calculation}

All eligible children visiting the study site were enrolled consecutively during the 5 months study period. Using an estimated HBV prevalence of $8.1 \%$ in HIV-infected Cameroonians from the CAMPHIA survey [15], a Zscore at $95 \%$ confidence interval $(Z=1.96)$, and an error rate of $6 \%$, the following formula was used to calculate the sample size ( $N=80$ participants):

$$
\mathrm{N}(\text { size })=Z^{2} \mathrm{x} \frac{\mathrm{P}(1-\mathrm{P})}{(\mathrm{i})^{2}}=79.4
$$

\section{Enrolment of participants}

Following a consecutive sampling strategy, study participants were enrolled during their routine clinic attendance at the study site (EHC). Inclusion criteria were: (a) be HIV-positive; (b) be aged $\leq 15$ years old; (c) have an unknown HBV status; (d) be registered for monitoring at the study site; (d) not being transferred from another health facility; (e) have maternal/guardian informed consent for participation. Any child fulfilling the aforementioned criteria was excluded if unable to provide a blood sample.

\section{Data collection}

After consenting, a standard questionnaire was administered to the respective mother or guardian of eligible CLHIV, covering data on socio-demographic information (sex, age, region, origin, mother-child HBV risk factors) and epidemiological and clinical information, ART history, adherence information during pregnancy, delivery mode, infant feeding option, knowledge of maternal HBV status, maternal and child HBV vaccination history, possible exposure of the child to HBV, etc. For participants aged 11 years and above with high risk to suxual active, the questionnaire was filled, following by an interview in order to get more information on their sexual behaviours and others factors exposing to HBV in relation with their age range. Data were also verified and completed using the medical records available at the health facility.

\section{HBV testing}

A total of $5 \mathrm{~mL}$ of whole blood was collected in dry tubes by venipuncture from each study participant; after centrifugation, serum samples were separated from whole blood and stored at $-20^{\circ} \mathrm{C}$. Serum samples were then tested for HBV serological testing at the BIOSANTE INTERNATIONAL laboratory located close to the clinical site (EHC) in Yaounde, Cameroon.

For the evaluation of HBV prevalence, HBV serological testing targeting $\mathrm{HBsAg}$ was performed in duplicates using enzyme immuno-assay as per manufacturer's instructions (EIA-HBsAg test Kit-Rapid Labs, United Kingdom). Results were interpreted by calculating the mean of optical density of the duplicates with reference to the cut-off values as per the manufacturer's interpretation. According to the manufacturer, invalid results were specimens with absorbance to cut-off ratio between 0.9 and 1.1 and imposing another retesting of these specimens in duplicates instantaneously or repeat the test one month later.

For evaluation of the diagnostic performance of RDTs, the two lateral flow immuno-chromatographic assays for the detection of HBsAg, HBSAg DiaSpot ${ }^{\circ}$ rapid test and HBV 5 in 1 kit (Hepatitis B 5 markers in one rapid diagnosis test), were tested on each sample as per the manufacturer's instructions. Results were reported either as positive, negative or invalid. Using the EIA (the gold standard), a technic routinely used as the confirmation test of HBV infection,. Sensitivity, specificity, positive predictive value (PPV) and negative predictive values (NPV) were calculated as previously described by Marcillat et al [19].

\section{Statistical analysis}

Data were entered into an excel spreadsheet, doublechecked for accuracy and cleaning, then closed for data analysis. The cleaned dataset was then transferred into Epi info 7.0 for statistical analyses. HBV prevalence was defined as low if $<2 \%$, moderate if between 2 and $7 \%$ and high if $\geq 8[20]$. The comparison of categorical variable was done using a $\mathrm{X}^{2}$ test or Fisher exact test wherever applicable, and $p$-value $<0.05$ was considered as statistically significant.

\section{Results}

\section{Characteristics of study participants}

A total of 83 eligible participants were finally included in the study. The sex distribution was slightly different (54.2\% female vs. $45.80 \%$ male); the mean age was 8.7 ( \pm 3.8) years and distributed as follows: $15.7 \%(13 / 83)$ aged [0-5[, 36.1\% (30/83) aged [5-10[and 48.2\% aged [10-15] years (Table 1 ).

Regarding maternal history of HBV during pregnancy, 83.1\% (69/83) had no knowledge of their HBV status vs. $16.9 \%$ (who already had documented HBV results), of whom only one was reported HBsAg positive. Regarding HBV-vaccine, only five mothers $(6.0 \%)$ declared to have received anti-HBV vaccine. Regarding ART exposure, 
Table 1 Sociodemographic and basic clinical data of the study population

\begin{tabular}{|c|c|}
\hline Overall study participants & $83(100 \%)$ \\
\hline CD4 cells count, cells $/ \mathrm{mm}^{3}$, median [IQR] & $1031[830-1330]$ \\
\hline \multicolumn{2}{|l|}{$V L$} \\
\hline$<50$ & $21(25.3 \%)$ \\
\hline 50-999 & $13(15.6 \%)$ \\
\hline$\geq 1000$ & $15(18.1 \%)$ \\
\hline Unknown viremia & $34(41 \%)$ \\
\hline \multicolumn{2}{|l|}{ WHO clinical Stages, n(\%) } \\
\hline । & $72(86.7 \%)$ \\
\hline$\|$ & $6(07.2 \%)$ \\
\hline III & $3(3.6 \%)$ \\
\hline IV & $2(2.4 \%)$ \\
\hline \multicolumn{2}{|l|}{ Gender, n(\%) } \\
\hline Male & $38(45.8 \%)$ \\
\hline Female & $45(54.2 \%)$ \\
\hline Age (Year), Median [IQR[ & $9[6-12]$ \\
\hline \multicolumn{2}{|l|}{ Preterm babies } \\
\hline Yes & $5(6.0 \%)$ \\
\hline Non & $78(94.0 \%)$ \\
\hline \multicolumn{2}{|l|}{ Feeding option } \\
\hline Exclusive breastfeeding & $24(28.9 \%)$ \\
\hline Replacement feeding & $18(21.7 \%)$ \\
\hline Mixed feeding & $41(49.4 \%)$ \\
\hline \multicolumn{2}{|l|}{ Infant anti-HBV vaccination status } \\
\hline Yes & $50(60.3 \%)$ \\
\hline No & $33(39.7 \%)$ \\
\hline \multicolumn{2}{|l|}{ Bath at birth } \\
\hline Yes & $21(25.3 \%)$ \\
\hline No & $62(74.7 \%)$ \\
\hline \multicolumn{2}{|l|}{ Maternal HAART during pregnancy } \\
\hline TDF-3TC-EFV & $64(77.1 \%)$ \\
\hline Other regimens & $13(15.7 \%)$ \\
\hline ART-Naïve & $6(7.2 \%)$ \\
\hline \multicolumn{2}{|c|}{ Maternal anti-HBV vaccination status during pregnancy } \\
\hline Negative & $08(9.6 \%)$ \\
\hline Positive & $01(1.2 \%)$ \\
\hline Unknown & $69(83.1 \%)$ \\
\hline Vaccinated & $05(6.02 \%)$ \\
\hline
\end{tabular}

ART antiretroviral therapy, HAART Highly Active Antiretroviral Therapy, HAART Highly Active Antiretroviral Therapy, $H B V$ hepatitis B virus, IQR interquartile range, TDF-3TC-EFV tenofvoir-lamivudine-efavirenz, WHO World Health Organisation

7.2\% declared to be ART-naïve during pregnancy vs. 92.8\% ART-experienced mothers receiving either tenofovir-lamivudine-efavirenz (TENLAM-E) or other ART regimens (Table 1).
Based on children's immunization records, $60.2 \%$ (50/ 83) had a complete history of anti-HBV vaccination as per the national guidelines of the immunization program in Cameroon. None of the participants was sexually active (as per individual reports) and 77.1\% (64/83) did not have any history of blood transfusion (as per data from medical records) (Table 1).

\section{HBV prevalence}

The prevalence HBV, defined as the presence of HBsAg, was $2.4 \%(2 / 83)$ in the entire study population, indicating a moderateprevalence of HBV. The two HBV-positive cases were both female (aged 10-15 years), without any statistically significant difference as compared to males: $4.4 \%(2 / 45)$ vs. $0.0 \%(0 / 38), p=0.498$.

\section{Risk factors of HBV among study participants}

According to delivery mode, children borne by vaginal delivery were more likely to be infected with HBV as compared to those born by caesarean section: $2.4 \%$ vs. $0 \%$ respectively, $p=0.0018$ (Table 2 ).

According to knowledge of maternal HBV status during pregnancy, children born from mothers without knowledge of HBV as compared to those from mothers who knew their HBV status: $2.9 \%$ vs. $0 \%$ respectively, $p=0.0097$ (Table 2).

According to maternal history of ART, children born from mothers receiving ART consisting of TENLAM-E were appeared less likely to be infected with HBV as compared to those born from mother receiving other ART regimens: $1.5 \%(1 / 64)$ vs. $7.7 \%(1 / 13), p=0.48$; as shown in Table 2.

Additionally, the $2 \mathrm{HBV}$-positive children experienced exclusive breastfeeding, did not benefit from antiseptic bath at birth, had not received anti-HBV vaccination, and were from multiparous mothers, without any significant effect on HBV-positivity (Table 2).

\section{Performance of HBV rapid diagnosis tests}

Due to reagent shortage, a total of just 47 participants were tested with both the two RDT and with EIAHBsAg test Kit. The two (2) positive cases on EIA were reported as positive with HBSAg DiaSpot $^{\circ}$ rapid test (100\% sensitivity) while only one was reported as positive with HBV 5 in 1 , thus indicating a case of false negative result (50\% sensitivity). EIA-HBsAg test Kit produced 45 negative results, which were all reported as negative with HBSAg DiaSpot ${ }^{\circ}$ rapid test (100\% specificity) while 44/45 were reported as negative with HBV 5 in $1 \mathrm{kit}$, thus indicating one case of false positive result (97.8\% specificity) (Table 3 ).

With reference to EIA results, PPV of HBSAg DiaSpot ${ }^{\circ}$ and HBV 5 in 1 test kit was respectively 100\% (2/2) and. 50\% (1/2). Regarding NPV, HBSAg DiaSpot ${ }^{\circ}$ rapid test 
Table 2 Presence of HBsAg according to potential exposure

\begin{tabular}{|c|c|c|c|c|}
\hline Exposure & & $N$ & Positivity rate of HBsAg & $p$-value \\
\hline \multirow[t]{2}{*}{ Preterm baby } & Yes & 5 & 0 & \multirow{2}{*}{$\begin{array}{l}p=0.25 \\
X^{2}=1.3\end{array}$} \\
\hline & No & 78 & $2(2.6 \%)$ & \\
\hline \multirow[t]{3}{*}{ Feeding option } & Exclusive breastfeeding & 24 & $2(8.3 \%)$ & \multirow{3}{*}{$\begin{array}{l}p=0.41 \\
X^{2}=1.76\end{array}$} \\
\hline & Replacement feeding & 18 & 00 & \\
\hline & Mixed feeding & 41 & 00 & \\
\hline \multirow[t]{2}{*}{ Antiseptic bath at birth } & Yes & 21 & 00 & \multirow{2}{*}{$\begin{array}{l}p=1 \\
X^{2}=00\end{array}$} \\
\hline & No & 62 & $2(3.2 \%)$ & \\
\hline \multirow[t]{2}{*}{ Infant anti-HBV vaccination status } & Yes & 50 & 00 & \multirow{2}{*}{$\begin{array}{l}p=0.3 \\
x^{2}=1.063\end{array}$} \\
\hline & No & 33 & $02(6.1 \%)$ & \\
\hline \multirow[t]{4}{*}{ Maternal HBV status during pregnancy } & Negative & 08 & 00 & \multirow{4}{*}{$\begin{array}{l}p=0.0097 \\
X^{2}=11.374\end{array}$} \\
\hline & Positive & 01 & 00 & \\
\hline & Unknown & 69 & $02(2.9 \%)$ & \\
\hline & Vaccinated & 05 & 00 & \\
\hline \multirow[t]{2}{*}{ Delivery mode } & Normal vaginal & 82 & $02(2.4 \%)$ & \multirow{2}{*}{$\begin{array}{l}p=0.0018 \\
X^{2}=9.75\end{array}$} \\
\hline & Caesarean section & 01 & 00 & \\
\hline \multirow[t]{2}{*}{ Gravidity } & Primiparous & 19 & 00 & \multirow{2}{*}{$\begin{array}{l}p=0.94 \\
X^{2}=0.005\end{array}$} \\
\hline & Multiparous & 64 & $02(3.1 \%)$ & \\
\hline \multirow[t]{3}{*}{ Maternal HAART during pregnancy } & TENLAM-E & 64 & $1(1.5 \%)$ & \multirow{3}{*}{$\begin{array}{l}p=0.48 \\
x^{2}=2.459\end{array}$} \\
\hline & Other regimens & 13 & $1(7.7 \%)$ & \\
\hline & None & 6 & 0 & \\
\hline
\end{tabular}

HAART Highly Active Antiretroviral Therapy, TENLAM-E tenofovir-lamivudine-efavirenz, HBV hepatitis B virus; In bold are significant HBV prevalence

had a higher performance (100\%) compared to HBV 5 in 1 kit (97.8\%). Detailed results are shown in Table 3.

\section{Discussion}

In RLS with a high burden of HIV and HBV, evidence favouring an easy integrated care of HIV/HBV are necessary to scale-up interventions towards meeting the global target of eliminating both HIV and HBV by 2030, especially for children who are generally among the most vulnerable $[7,13]$. Achieving these goals require an understanding of the epidemiological burden, the risk factors involved, and knowledge on reliable HBV RDTs.

From our study participants, the sex distribution was similar (54.2\% female, ratio F/M of 5/4),similar to a distribution found in a previous study in the same setting [13]. Though some studies found men to be slightly

Table 3 Performance of HBV RDTs with reference to EIA

\begin{tabular}{|c|c|c|c|c|}
\hline & \multicolumn{2}{|l|}{ Diaspot } & \multicolumn{2}{|l|}{ HBV-5 } \\
\hline & Positive & Negative & Positive & Negative \\
\hline \multicolumn{5}{|c|}{ EIA (Gold standard) } \\
\hline Positive & 2 & 0 & 1 & 1 \\
\hline Negative & 0 & 45 & 1 & 44 \\
\hline Total & 2 & 45 & 2 & 45 \\
\hline
\end{tabular}

HBV-5 Hepatitis B 5 markers in one rapid diagnosis test, EIA Enzyme ImmunoAssay, $H B V$ hepatitis $B$ virus, $R D T$ rapid diagnostic tests higher in proportion [21-23], the reported distribution between girls and boys in our study is within the range of birth rate proportions in the country. This therefore ensures a possible representativeness of our findings to the target population of CLHIV in Cameroon [24]. With a mean age of 8.7 years old, our findings are concordant with previous reports (mean age of $7.3 \pm 3.6$ years in Nigeria) in 201 6[21], thus ensuring comparability. However, age distribution was different from a previous study, due to differences in the primary aims and eligibility conditions (mean age of 26.6 and min-max: 6- 59 months) [13].

HBV-positivity was relative moderate (2.4\%), and was similar to previous findings from the target populations in Cameroon (4.3\%) [13], and in other countries (2\% in Ethiopia [22], 1.6\% in Democratic republic of Congo [25], 1.2\% in Tanzania [26], 2.2\% in Malawi [27], 3.3\% in Thailand [28]). Compared to the highly endemic HBV among adult populations [15] or pregnant women (17, 5\%) [18], the relatively moderate pediatric HBV prevalence is probably due to the wide paediatric coverage of anti-HBV vaccination in Cameroon [29]. This moderate prevalence of $\mathrm{HBV}$ in children could be partly attributed to maternal ART containing essentially TENLAM-E (77.1\%), a regimen known to have molecules with antiviral activity (tenofovir and lamivudine) against HBV infection [7]. 
Regarding risk factors of HBV infection among these children, age 10-15 years appears with a higher (5\%) but non-significant risk $(p=0.78)$ of HBV acquisition compared to younger ones $(0 \%)$, as confirmed by previous studies [21, $22,30]$. Though non-significant, the presence of HBV only among in older children with advanced age, in a context of no reported sexual activity, suggests elow risk of HBV mother-to-child transmission and underscores the possibility of horizontal transmission of HBV(unsafe environment). Also, this may reflect the inability to achieve HBsAg clearance due to impaired immunity [31, 32]. Most importantly, the, hypothesis of low HBV prevalence or ART-tailoring $\mathrm{HBV}$-infection seems to be the most prominent, owing to the fact that co-infected mothers with positive $\mathrm{HBeAg}$, HBsAg and HBV DNA transmitted HBV to their children in Burkina-Faso [32].

Infants who experienced a vaginal delivery vs. Caesarean section are more at risk of $\mathrm{HBV}$ acquisition, as previously reported in China ( $R R=2.20,95 \%$ CI $1.02-4.74, p=0.04$ ) [33]. Of relevance, the two cases of positive HBV are from mothers with unknown HBsAg status during pregnancy, another factor significantly associated with HBV-positivity in CLHIV ( $p=0.0097)$, due to no preventive or prophylactic measure undertaken against HBV during delivery. This calls for a systematic HBV testing of each pregnant woman with unknown HBV status in the labour room and the use of anti-HBV serum for infants born to HBsAg-positive mothers, as currently practised not only the USA [34].

Children from mothers receiving ART consisting of TENLAM-E appeared to have a slightly lower risk of HBV acquisition. Though not significant, this difference may reflect the ability of the aforementioned regimen (containing tenofovir and lamivudine) to control HBV; this observation merits further assessment in larger studies. Of note, feeding option and antiseptic bath did not have any effect on the risk of HBV acquisition, thus suggesting the effectiveness of protective breastfeeding demonstrated in the prevention of mother to child transmission [35-38], pending confirmatory findings on $\mathrm{HBV}$ as the amniotic fluid may contain HBV DNA [39]. HBVpositivity was also in the frame of no anti-HBV vaccination, supporting the benefit of universal vaccination of children [40], for ensuring a consistent decline of HBV (i.e. $88.5 \%$ decline with HBV vaccine coverage in USA) [41].

Regarding the diagnostic performance of the two HBV RDTs, DiaSpot ${ }^{\oplus}$ rapid test has excellent intrinsic performance (100\% sensitivity, $100 \%$ specificity) and extrinsic performance (100\% PPV and 100\% NPV). However, the HBV 5 in 1 kit revealed poorer intrinsic performance (50\% sensitivity, 97.8\% specificity) and extrinsic performance (50\% PPV and 97.8\% NPV). These observations are highly concordant with previous findings on pooled analysis of HBV 5 in 1 kit showing sensitivity and specificity lower than the World Health Organisation (WHO) prequalified RDTs among people living with HIV (pooled sensitivity and specificity of 72.3 and $99.8 \%$ respectively) [42-47]. Thus, in a context of limited resources, Diaspot test should be prioritised for HBV testing on an individual living with HIV-infection [48]. The observed difference in sensitivities of both RDTs could be due to the fact that HBV variants are not effectively recognized by the antibodies coated on the test kit, leading to loss of or weakened epitope binding affinity [49].

The relative low-rate of $\mathrm{HBV}$ could also be due to events of occult HBV infection, generally characterised by a negative HBsAg and positive HBV DNA. This suggests further studies using molecular diagnostic platforms $[4,50]$. Of note, vaccine-escape mutants within the 'a' determinant of the $S$ genes are not genuinely recognized by conventional diagnostic tests as the wild type particles [50]. More so, hypothesis of occult hepatitis B in HIVpositive persons exposed to tenofovir- or lamivudinecontaining ART regimens should be taken into consideration while explaining this low HBsAg prevalence and the reduced clinical sensitivity of the kit HBV-5 in 1[42]. A wider sampling and the use molecular assays would be more informative.

\section{Study limitations}

Knowledge on the effective routes of HBV transmission, either vertical or horizontal, could not be delineated in the current study. Also, a thorough performance of both rapid tests under evaluation requires a higher sample size, which in our study was hindered by limited availability of financial resources. Further studies covering these epidemiological and diagnostic aspects would be relevant.

\section{Conclusion}

Among paediatric populations living with HIV in an urban African setting, HBV-infection appears endemic at a moderate prevalence, suggesting a decreased burden possible attributed to preventives measures including the wide vaccine coverage. In this context, priority interventions towards mothers with unknown HBV-status and those practicing vaginal delivery (encouraging caesarean section for HBV-positive mothers) would strengthen current efforts in eliminating pediatric $\mathrm{HBV}$ in endemic countries. In such countries, coupled with limited resources, Diaspot test appears more reliable to rollout HBV-infection in the population of CLHIV and speedup the global targets for HBV elimination.

\section{Abbreviations}

ART: Antiretroviral therapy; DNA: Desoxyribo nucleotidic acid; ElA: Enzymes immuno assay; ELISA: Enzymes linked immunosorbent assay; HAART: Highly active antiretroviral therapy; HBeAg: Hepatitis B envelop antigen;

HBsAg: Hepatitis B surface antigen; HBV-5: Hepatitis B 5 markers in one rapid 
diagnosis test; HIV: Human immunodeficiency virus,; IQR: Interquartile range, NPV: Negative predictive value; PCR: Polymerase chain reaction; PPV: Positive predictive value; TENLAM-E: Tenofovir-lamivudine-efavirenz; WHO: World health organisation,

\section{Acknowledgements}

We would like to thanks children, mother of children and the site staff for their cooperation during our activities.

\section{Authors' contributions}

Designed the study: FJ, RKW, NNC, NNAE, FS, TTMC; Planned and performed the experiments: FJ, RKW, NPS, TNC, FS; Analysed and interpreted the data: TS, NPS, TNC, VC; Initiated the manuscript: FJ, RKW, NNC; Revised the manuscript: All the authors; Approved the final version of the manuscript: All the authors.

\section{Funding}

The present study was sponsored by internal funding from the study investigators.

\section{Availability of data and materials}

All the data on which the conclusions of the manuscript are drawn are duly presented in the main paper and related tables and figures.

\section{Ethics approval and consent to participate}

Ethical clearance was obtained from the institutional Ethics Committee

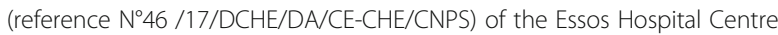
and the director of CHE delivered an administrative authorization for the research activities. Prior to enrolment of each participant, the study information sheet was given to the respective mother or guardian. A written informed consent was then provided prior to the child enrolment. Confidentiality was ensured throughout the data collection and processing by using specific identification numbers; justice was ensured by providing results of EIA HBsAg to all participants free of charge, for clinical utility.

\section{Consent for publication}

Not applicable.

\section{Competing interests}

The authors declare that they have no competing interests.

\section{Author details}

${ }^{1}$ Chantal BIYA International Reference Centre (CIRCB) for Research on HIV/ AIDS prevention and management, Yaounde, Cameroon. ${ }^{2}$ Faculty of Medicine and Biomedical Sciences of the University of Yaounde 1, Yaounde, Cameroon. ${ }^{3}$ National HIV Drug Resistance Working Group, Ministry of Public Health, Yaounde, Cameroon. ${ }^{4}$ Faculty of Science, Department of Microbiology and Parasitology, University of Buea, Buea, Cameroon. ${ }^{5}$ Department of Health Sciences, Estuary Academy and Strategic Institute (IUES/INSAM/ISSAS), Higher Institute of Health Applied Sciences, University of Buea, Buea, Cameroon. ${ }^{6}$ Faculty of Science, Department of Biochemistry, University of Yaounde 1, Yaounde, Cameroon. ${ }^{7}$ National Public Health Laboratory, Ministry of Public Health, Yaounde, Cameroon. ${ }^{8}$ Higher Institute of Sciences and Techniques Applied to Health (ISTASS), Yaounde, Cameroon. ${ }^{9}$ Laboratoire Biosanté International, Yaounde, Cameroon. ${ }^{10}$ Essos Hospital Centre (CHE), Yaounde, Cameroon. ${ }^{11}$ Cameroon Evangelic University, Bandjoun, Cameroon. ${ }^{12}$ UNESCO Board of Biotechnology, University of Rome Tor Vergata, Rome, Italy. ${ }^{13}$ Higher Teacher Training College (ENS), University of Yaounde 1, Yaounde, Cameroon.

Received: 21 May 2019 Accepted: 25 September 2019 Published online: 22 October 2019

\section{References}

1. UNAIDS, Global Report: UNAIDS report on the global AIDS epidemic 2013, Geneva,Switzerland,2013.Available at: http://www.unaids.org/en/media/ unaids/contentassets/documents/epidemiology/2013/gr2013/UNAIDS_ Global_Report_2013_en.pdf. Accessed March 14, 2014.

2. Matthews PC, Geretti AM, Goulder PJ, Klenerman P. Epidemiology and impact of HIV coinfection with hepatitis B and hepatitis $C$ viruses in sub-
Saharan Africa. J Clin Virol. 2014;61(1):20-33. https://doi.org/10.1016/j.jcv. 2014.05.018

3. Larsen C, Pialoux G, Salmon D, Antona D, Piroth L, Le Strat Y, et al. Prévalence des co-infections par le virus des hépatites $B$ et $C$ dans la populpation $\mathrm{VH}+$, France, juin. Bulletin Epidémiologique Hebdomadaire. 2005;23:109-12.

4. Salpini R, Fokam J, Ceccarelli L, Nanfack A, Torimiro J, Sarmati L, et al. High Burden of HBV-Infec- tion and Atypical HBV Strains among HIV-infected Cameroonians. Curr HIV Res. 2016;14(2):165-71.

5. World Health Organisation, Protocol 7. HIV/AIDS treatment and care. Clinical protocols for the WHO European Region. Geneva: WHO; 2012. Management of hepatitis B and HIV coinfection

6. Sogni P, Transmission materno-infantile des hépatites virales B et C. la lettre de l'hépato-gastroentérologue-n²-vol. V- Juillet-Août 2002.

7. Healy SA, Gupta S, Melvin AJ. HIV/HBV coinfection in children and antiviral therapy. Expert Rev Anti-Infect Ther. 2013;11(3):251-63. https://doi.org/10. 1586/eri.13.2.

8. Kew MC. Progress towards the comprehensive control of hepatitis B in Africa: a view from South Africa. Gut. 1996;38(Suppl. 2):S31-6 [PubMed: 8786050].

9. Ayoola E. Viral hepatitis in Africa. In: Aj Zuckerman E, editor. Viral hepatitis and liver disease. Alan R Liss. New York: NY, USA; 1988. p. 161-9.

10. Shiraki K, Yoshihara N, Kawana T, Yasui H, Sakurai M. Hepatitis B surface antigen and chronic hepatitis in infants born to asymptomatic carrier mothers. Am J Dis Child. 1977;131(6):644-7.

11. Beasley RP, Shiao IS, Wu TC, Hwang LY. Hepatoma in an HBsAg carrierseven years after perinatal infection. JPediatr. 1982;101(1):83-4.

12. Mast EE, Margolis HS, Fiore AE, Brink EW, Goldstein ST, Wang SA, et al. A comprehensive immunization strategy to eliminate transmission of hepatitis $B$ virus infection in the United States: recommendations of the Advisory Committee on Immunization Practices (ACIP) part 1: immunization of infants, children, and adolescents. MMWR Recomm Rep. 2005;54(RR-16):1-31.

13. Njom Nlend AE, Nguwoh PS, Ngounouh CT, Tchidjou HK, Pieme CA, Otélé JM, Penlap V, Colizzi V, Moyou RS, Fokam J. HIV-Infected or -Exposed Children Exhibit Lower Immunogenicity to Hepatitis B Vaccine in Yaoundé, Cameroon: An Appeal for Revised Policies in Tropical Settings? PLoS One. 2016;11(9):e0161714. https://doi.org/10.1371/journal.pone.0161714.

14. Comité national de lutte contre le VIH, 2014. Rapport annuel 2014 des activites de lutte contre le VIH/SIDA et les IST au Cameroun, vers une génération sans sida. Mars 2015 (http://www.cnls.cm/sites/default/files/ rapport_annuel_cnls_2014.pdf).

15. Njouom R, Fontanet A, 2011.Projet ANRS 12289 Epidémiologie des hépatites virales B, C, et delta au Cameroun: analyse des échantillons de l'Enquête Démographique de Santé 2011. Centre Pasteur du Cameroun

16. Sokal EM, Kelly DA, Mizerski J, Badia IB, Areias JA, Schwarz KB, et al. Longterm lamivudine therapy for children with $\mathrm{HBeAg}$ positive chronic hepatitis B. Hepatology. 2006;43(2):225-32.

17. Sheng YJ, Liu JY, Tong SW, Hu HD, Zhang DZ, Hu P, Ren H, et al. Lamivudine plus adefovir combination therapy versus entecavir monotherapy for lamivudine-resistant chronic hepatitis B: a systematic review and meta-analysis. Virol J. 2011;8:393.

18. Ikomey GM, Jacobs GB, Tanjong B, Mesembe MT, Eyoh A, Lyonga E, et al. Evidence of $c 0$ and triple infections of hepatitis $b$ and $c$ amongst hiv infected pregnant women in buea, Cameroon. Health Sci Dis. 2016;17:2.

19. Marcillat S, Diagbouga S, Chatterjee K, Choudhary M. Evaluation of Vikia HbsAg, a new immunochromatographic test for the qualitative detection of HBs antigen in serum, plasma and whole human samples. J Clin Microbiol. 2007;1(2):67-74

20. Milas J, Ropac D, Mulic R, Milas V, Valek I, Zoric I, et al. Hepatitis B in the family. Eur J Epidemiol. 2000;16(3):203-8.

21. Uleanya ND, Nwokoye IC, Emodi IF, Obidike EO, Ikefuna AN, Eze JC, Ndu IK. The prevalence liver function and immunologic status of children with Hiv and hepatitis B virus Coinfection in Enugu, Nigeria. Afr J Infect Dis. 2016; 10(2):61-8.

22. Bayeh A, Yohanes Z, Wondemagegn M, Mulugeta K, Getachew K. Seroprevalence of hepatitis B and C viruses and risk factors in HIV infected children at the felgehiwot referral hospital, Ethiopia. BMC Research Notes. 2014;7:838 (http://www.biomedcentral.com/1756-0500/7/838).

23. Zhou S, Zhao Y, He Y, Li H, Bulterys M, Sun X, et al. Hepatitis B and hepatitis $C$ seroprevalence in children receiving antiretroviral therapy for human immunodeficiency virus-1 infection in China, 2005-2009. J Acquir Immune Defic Syndr. 2010;54(2):191-6. https://doi.org/10.1097/ QAl.0b013e3181c99226. 
24. Rapport préliminaire sur la prévalence du VIH : Enquête Démographique et de Santé et à Indicateurs Multiples Cameroun EDS-MICS 2011. Institut National de la Statistique; 2012.

25. Katabula M, Mafuta ME, Ngoma AM, Beya PM, Yuma S, Aketi L, et al. Prevalence and risk factors for hepatitis C virus, hepatitis B virus and immunodeficiency virus in transfused children in Kinshasa. Indian J Pediatr. 2013;80:659-62.

26. Talatela SP, Matee MI, Munubhi EK. Seroprevalence of hepatitis B and C viral co-infection among children infected with human immunodeficiency virus attending the pediatric HIV care and treatment Centre at Muhimbili National Hospital in Dar-es-salaam, Tanzania. BMC Public Health. 2007;7:338. https://doi.org/10.1186/1471-2458-7-338

27. Varo R, Buck WC, Kazembe PN, Phiri S, Andrianarimanana D, Weigel R, Seroprevalence of CMV, HSV-2 and HBV among HIV-infected Malawian children: a cross-sectional survey. J Trop Pediatr. 2016;62(3):220-6.

28. Tsuchiya N, Pathipvanish P, Rojanawiwat A, Wichukchinda N, Koga I, Koga $M$, et al. Chronic hepatitis B and C co-infection increased all-cause mortality in HAART-naïve HIV patients in northern Thailand. Epidemiol infect. 2012. https://doi.org/10.1017/S0950268812002397.

29. Kfutwah AK, Tejiokem MC, Njouom R. A low proportion of HBeAg among HBsAg-positive pregnant women with known HIV status could suggest low perinatal transmission of HBV in Cameroon. Virol. J. 2012;9:62.

30. WHO., 2004. Estimated total deaths by cause and WHO Member State, 2002. Department of Measurement and Health Information. https://www.who.int/ evidence/bod, October 4th, 2017.

31. Anigilaje EA, Olutola A. Prevalence and clinical and immunovirological profile of human immunodeficiency virus-hepatitis B coinfection among children in an antirethroviral therapy programme in Benue State, Nigeria. ISRN Pediatr. 2013. https://doi.org/10.1155/2013/932697.

32. Levy V, Grant RM. Antiretroviral therapy for hepatitis B virus-HIV co-infected patients: promises and pitfalls. Cl in Infect Dis. 2006:43:904-10.

33. Ilboudo D, Simpore J, Ouermi D, Bisseye C, Sagna T, Odolini S, et al. Towards the complete eradication of mother-to-child HIV/HBV co-infection at Saint Camille medical Centre in Burkina Faso, Africa. Braz J Infect Dis. 2010;14:219-24

34. Xu H, Zeng T, Liu JY, Lei Y, Zhong S, Sheng YJ, et al. Measures to Reduce Mother-to-Child Transmission of Hepatitis B Virus in China: A Meta-Analysis. Dig Dis Sci. 2014;59(2):242-58.

35. CDC. Prevention of Hepatitis B Virus Infection in the United States: Recommendations of the Advisory Committee on Immunization Practices. MMWR Recomm and Rep. 2018;67:1.

36. Becquet $\mathrm{R}$ et al. Mortality in breastfed and formula-fed children born to HIVinfected women in a PMTCT project in Abidjan (Cote d'lvoire): Ditrame plus ANRS 1202. Abstract 62, 2nd IAS Conference on HIV pathogenesis and treatment, Paris, France, 13-16 July 2003.

37. The Breastfeeding and HIV International Transmission Study (BHITS) Group. Late Postnatal Transmission of HIV-1 in Breastfed Children: an individual patient data meta-analysis. J Infect Dis. 2004; in press.

38. Rollins $\mathrm{N}$, et al. Feeding mode, intestinal permeability and neopterin excretion: a longitudinal study in infants of HIV-infected south African women. J Acquir Immune Defic Syndr. 2001;28:132-9.

39. WHO. HIV transmission through breastfeeding. A review of available evidence. Geneva: World Health Organization; 2004.

40. Ph. Sogni, Transmission materno-infantile des hépatites virales B et C. la lettre de I'hépato-gastroentérologue-n 4-vol.V- Juillet-Août 2002.

41. Njoya O, Essi MJ, Fouwou C, Mekongo MO, Ndam ECN. Facteurs associés à la transmission mère-enfant de l'hépatite virale B au Cameroun. AFRAVIH 2014, Montpellier, France, 27 Avril - 01 Mai.

42. CDC. Surveillance data for acute viral hepatitis-United States, 2008. Atlanta: US Department of Health and Human Services, CDC; 2010. https://www.cdc gov/hepatitis/statistics/2008surveillance/index.htm

43. WHO (2017). Guidelines on hepatitis B and C testing. Geneva: World Health Organization; 2017. Licence: CC BY-NC-SA 3.0 IGO

44. Davies J, van Oosterhout JJ, Nyirenda M, Bowden J, Moore E, Hart IJ, et al. Reliability of rapid testing for hepatitis $B$ in a region of high HIV endemicity. Trans R Soc Trop Med Hyg. 2010;104(2):162-4.

45. Geretti AM, Patel M, Sarfo FS, Chadwick D, Verheyen J, Fraune M, et al. Detection of highly prevalent hepatitis B virus coinfection among HIVseropositive persons in Ghana. J Clin Microbiol. 2010;48(9):3223-30.

46. Hoffmann CJ, Dayal D, Cheyip M, McIntyre JA, Gray GE, Conway S, et al. Prevalence and associations with hepatitis $B$ and hepatitis $C$ infection among HIV-infected adults in South Africa. Int J STD AIDS. 2012;23(10):e10-e3.
47. Franzeck FC, Ngwale R, Msongole B, Hamisi M, Abdul O, Henning L, et al. Viral hepatitis and rapid diagnostic test based screening for HBsAg in HIVinfected patients in rural Tanzania. PLoS One. 2013;8(3):e58468.

48. Honge B, Jespersen S, Medina C, Te D, da Silva Z, Ostergaard L, et al. Hepatitis B virus surface antigen and anti-hepatitis $C$ virus rapid tests underestimate hepatitis prevalence among HIV-infected patients. HIV Med. 2014;15(9):571-6.

49. Raj AA, Subramaniam T, Raghuraman S, Abraham P. Evaluation of an indigenously manufactured rapid immunochromatographic test for detection of HBsAg. Indian J Pathol Microbiol. 2001;44:413-4.

50. Dodson SF, Issa S, Araya V, Gayowski T, Pinna A et al. Infectivity of hepatic allografts with antibodies to HBV. Transplantation. 1997;64:1582-4.

\section{Publisher's Note}

Springer Nature remains neutral with regard to jurisdictional claims in published maps and institutional affiliations.
Ready to submit your research? Choose BMC and benefit from:

- fast, convenient online submission

- thorough peer review by experienced researchers in your field

- rapid publication on acceptance

- support for research data, including large and complex data types

- gold Open Access which fosters wider collaboration and increased citations

- maximum visibility for your research: over $100 \mathrm{M}$ website views per year

At BMC, research is always in progress.

Learn more biomedcentral.com/submissions 